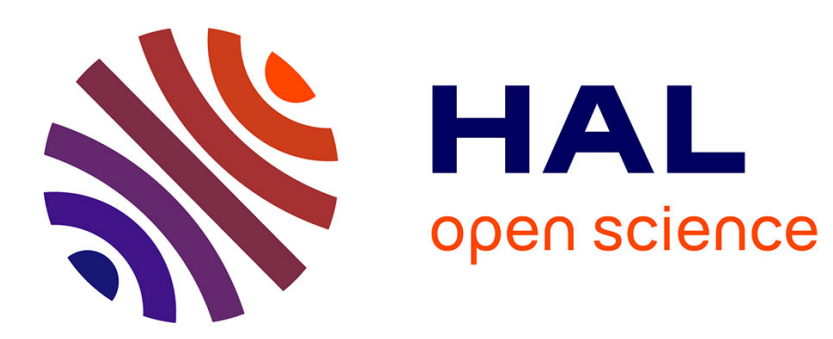

\title{
Characterization of mixing in a stirred tank by planar laser induced fluorescence (PLIF)
}

Ahmed Fall, Olivier Lecoq, René David

\section{To cite this version:}

Ahmed Fall, Olivier Lecoq, René David. Characterization of mixing in a stirred tank by planar laser induced fluorescence (PLIF). Chemical Engineering Research and Design, 2001, 79 (A8), pp.876-882. 10.1205/02638760152721073 . hal-01717493

\section{HAL Id: hal-01717493 \\ https://hal.science/hal-01717493}

Submitted on 6 Nov 2019

HAL is a multi-disciplinary open access archive for the deposit and dissemination of scientific research documents, whether they are published or not. The documents may come from teaching and research institutions in France or abroad, or from public or private research centers.
L'archive ouverte pluridisciplinaire HAL, est destinée au dépôt et à la diffusion de documents scientifiques de niveau recherche, publiés ou non, émanant des établissements d'enseignement et de recherche français ou étrangers, des laboratoires publics ou privés. 


\title{
CHARACTERIZATION OF MIXING IN A STIRRED TANK BY PLANAR LASER INDUCED FLUORESCENCE (P.L.I.F.)
}

\author{
A. FALL, O. LECOQ and R. DAVID \\ 'Laboratoire de Génie des Procédés des Solides Dirisés' - UMR CNRS 2392, Ecole des Mines d'Albi-Carmaux (E.M.A.C.), Campus Jarlard, \\ 81013 ALBI CT cedex 09, France.
}

\begin{abstract}
$\mathrm{T}$ he mixing of two water feedstreams is investigated in a $0.02 \mathrm{~m}^{3}$ continuous stirred tank, from concentration measurements. These measurements are carried out with a laser sheet in a very thin vertical plane through the vessel tangent to the impeller. The proportionality between the grey level obtained by planar laser induced fluorescence and the local concentration has been previously determined. The fields of instantaneous concentration, temporal variance and mixing index are processed from the grey level images.
\end{abstract}

Keywords: mixing; mixing index; laser sheet; fluorescence; stirred tank.

\section{INTRODUCTION}

Solid particles obtained in industry by precipitation (reaction crystallization) are generally produced in mechanically stirred tanks, or in jet mixers. In these processes, two liquid streams come into contact, but the process is more or less controlled.

Precipitation supersaturations originate from a chemical reaction and thus are very high ${ }^{1}$. Furthermore, the effects of contacting and mixing conditions of reactants play an essential role on the nucleation and crystal size distribution ${ }^{2}$. Indeed, if the mixing of both reactants is imperfect in the stirred tank, the concentration pattern will not be homogeneous and supersaturation heterogeneities will be created. Consequently, nucleation and crystal growth rates will vary in the mixer from one point to another.

As a mixing model, the fluorescence properties of a solution mixed with pure water in a transparent tank are used, which is crossed by a planar laser sheet. During the first moments of mixing, the mixing of the two tracers is similar to the mixing of two reagents in ionic precipitation. Indeed, there is no significant consumption of the reactants during the first seconds of mixing, owing to the small size of nuclei produced and to the time scales of the crystal growth, which are much larger than those of nucleation ${ }^{3}$. As a result, mixing in ionic precipitation can be characterized by studying the mixing of two inert tracers, or the mixing of a single tracer in solution with pure solvent, each fluid being injected by two separate feed tubes. The laser sheet visualization method has been used by Mahouast ${ }^{4}$, and developed in a $0.02 \mathrm{~m}^{3}$ mechanically stirred tank by Houcine et al..$^{5}$ and adapted at the pilot scale by Marcant et al. ${ }^{6}$. The laser induced fluorescence technique (L.I.F.), which is non-intrusive like tomography ${ }^{7}$, can help to optimize the geometry of the mixers, the feed rates or the positions and shape of the injectors. It is based on the stimulation of fluorescence by laser and the measurement of the emitted light. For low tracer concentrations the fluorescent intensity is proportional to the local concentration and to the power of the incident laser light. Previous workers have used a CCD camera ${ }^{4-6,8}$, a photomultiplier ${ }^{9}$, and a line scan camera ${ }^{10}$. They measured the fluorescent light intensity, respectively in a plane, at a point, and along a line. The planar laser induced fluorescence technique (P.L.I.F.) allows characterizing mixing in any plane crossing the flow defined by the laser sheet. This technique is based on the fluorescence of organic substances induced by a laser sheet and coupled with image analysis. The originality of this study, compared to previous works ${ }^{4-6}$, lies (a) in the fact that the laser sheet is very thin (down to $100 \mu \mathrm{m}$ ); (b) the camera is much more sensitive and finally; (c) more powerful tools are used for image processing.

The aim of this paper is to describe and validate the PLIF set up designed for fast and precise characterization of contacting and mixing of one inert tracer and pure water.

\section{MEASUREMENT TECHNIQUE AND EXPERIMENTAL SET-UP}

\section{Principle}

Several organic molecules in solution, like fluoresceine or rhodamine B exhibit a fluorescence phenomenon when they are stimulated by laser light. For low tracer concentrations the intensity of fluorescence is proportional to the local concentration of tracer and to the power of the incident laser light. The fluorescence is emitted with a wavelength (about $590 \mathrm{~nm}$ ) higher than that of the laser $(520 \mathrm{~nm})$. Its intensity is filtered and monitored by a high sensitive camera.

\section{Procedure}

The first set measurements are performed to establish the grey level images in the following cases: 
- the tank is filled with water. It provides for the grey level field of the background: $N G_{o b}(x, y, t)$;

- the stirred tank is filled with a fluorescent tracer solution. Its concentration is the mixing concentration during the experiment in the completely homogeneous state $C_{m p}$. It yields the grey level field corresponding to the perfect mixing images;

- finally, two water feedstreams (one containing the fluorescent tracer) supply the stirred tank, yielding the grey level field: $N G(x, y, t)$.

For a diverging laser sheet Houcine et $a .^{5}$ derived the relations between:

- the instantaneous local concentration of tracer and the grey level $N G(x, y, t)$ of the image:

$$
C(x, y, t)=\frac{N G(x, y, t)-\overline{N G}_{o b}(x, y)}{\overline{N G}_{C_{m p}}(x, y)-\overline{N G}_{o b}(x, y)} C_{m p}
$$

- between the grey level $N G(x, y, t)$, the power of laser source $P_{o}$ and the tracer local concentration $C(x, y, t)$ :

$$
N G(x, y, t)=K P_{o} C(x, y, t) \exp \left[-\left(\varepsilon_{i} L+\varepsilon_{e} L^{\prime}\right) C_{m p}\right]
$$

Where $\overline{N G_{o b}}(x, y)$ and $\overline{N G_{C_{m p}}}(x, y)$ are the average grey levels of the background and the perfect mixing, respectively, $\varepsilon_{i}$ and $\varepsilon_{e}$ are the extinction coefficients of incident laser light and emitted fluorescence light, $L$ is the depth of penetration of the laser beam into the tracer solution, $L^{\prime}$ is the optic path of the fluorescent light in the tracer solution, $K$ is a constant grouping physical and geometrical parameters

Equation (1) takes into account the attenuation of the intensity along the optical path, approximately identical for $N G_{C_{m p}}(x, y, t)$ and $N G(x, y, t)$. Equation (2) is intended to determine the operating conditions of tracer concentration and power favourable to obtaining a proportionality and a great sensitivity between the grey level and fluorescent dye concentration. Thus, it was possible to determine the intensity of fluorescence emission as a function of:

(a) the tracer concentration: the tank is filled with different solution of homogeneous concentration, varying between 0 and $40 \times 10^{-6} \mathrm{~kg} \mathrm{~m}^{-3}$;

(b) the laser intensity: the tank is irradiated at $P_{o}$ increasing, varying between 0 and $2 \mathrm{~W}$.

\section{Experimental}

The scheme of the apparatus used in this work is shown in Figure 1. The experiments are carried out in a standard type stirred tank of $0.02 \mathrm{~m}^{3}$. The cylindrical vessel of internal diameter $T=0.29 \mathrm{~m}$ is placed inside a square vessel filled with water in order to reduce problems associated with refraction by curved surfaces. Both vessels are made of a transparent material of optical quality Altuglass (PMMA). Four baffles of width $T / 10$ and thickness $T / 100$ are provided at intervals of $90^{\circ}$ against the wall of the inner tank. The six-bladed Rushton turbine in Altuglass is coupled to a stainless steel shaft which has an external diameter of $10 \mathrm{~mm}$. The impeller diameter and bottom clearance are equal to $H / 3$, where $H$ represents the height of the liquid in the tank. The other dimensions of the stirred tank are represented in Figure 2. The stirring speed is fixed at $N=110 \mathrm{rpm}$. The optical device includes a laser diode, with an emission wavelength of $520 \mathrm{~nm}$ and with a maximum power $P_{o}=2 \mathrm{~W}$. When crossing the diaphragm, the laser beam is focused by a mirror and is spread out into a very thin sheet (down to $100 \mu \mathrm{m}$ ) using a POWELL lens. A CCD camera, of total exposure time $35 \mathrm{~ms}$, fitted with a sharp cut-off high pass filter takes 9 images per second. It gives high resolutions down to ten micrometers, since it provides for images of $1280 \times 1024$ pixels encoded on 4096 grey levels. The camera and the laser are jointly assembled

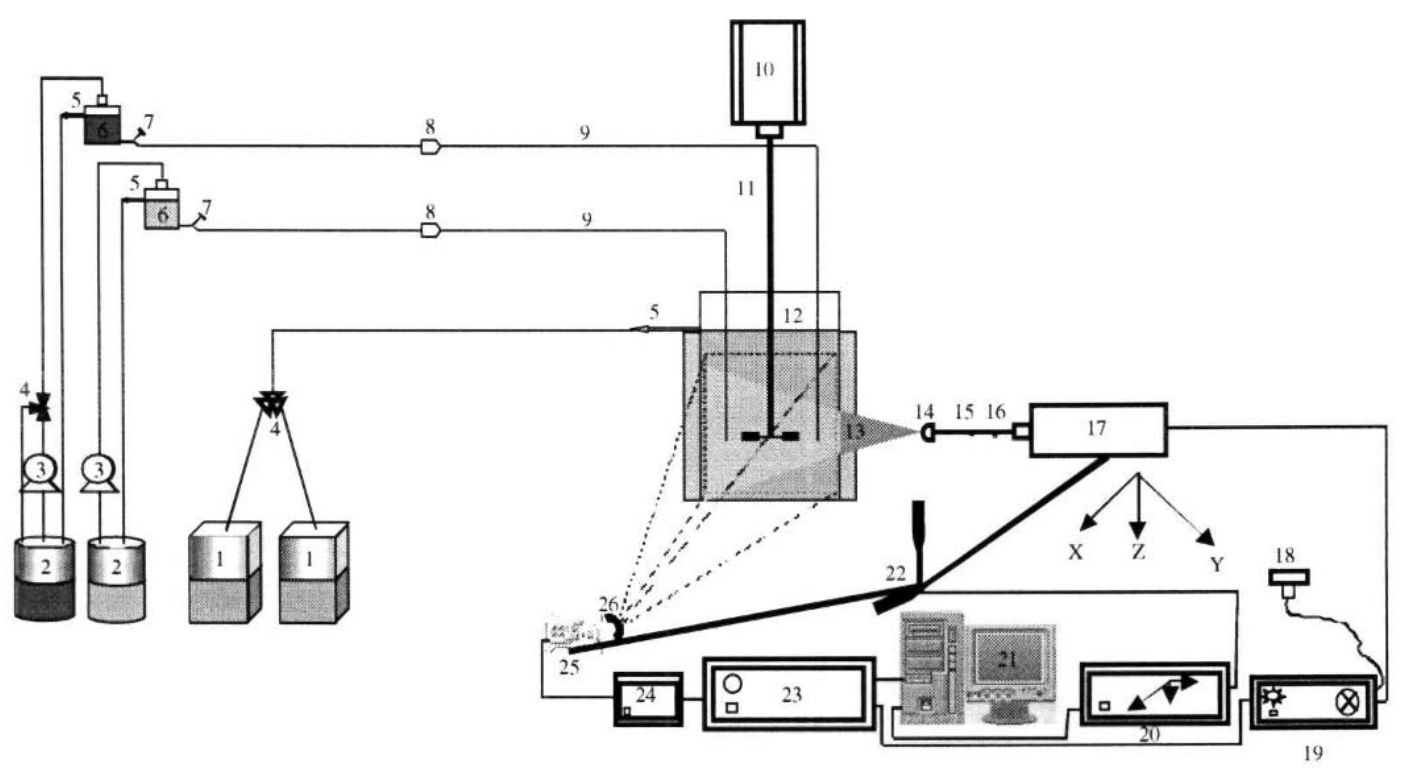

Figure 1. Experimental set-up: (1) storage tanks; (2) feed tanks; (3) pumps; (4) valve; (5) outlet; (6) reservoirs; (7) taps; (8) flow meter; (9) feed tubes; (10) motor; (11) stirrer; (12) mixing tank; (13) laser sheet; (14) Powell lens; (15) mirror; (16) diaphragm; (17) 2 W diode-pumped laser millennia IIs (Nd: YVO 4 ): excitation wavelength at $520 \mathrm{~nm}$; (18) control module; (19) internal diode power supply; (20) displacement remote control; (21) computer; (22) displacement system; (23) processor; (24) video power supply; (25) DANTEC CCD-camera: HiSense ${ }^{\mathrm{R}}$ PIV/PLIF; (26) high-pass filter: Sharp-cut glass filter (570 nm) placed on the lens of the camera to remove reflections of the laser light from the fluorescent signal to achieve a high signal-to-noise ratio. 


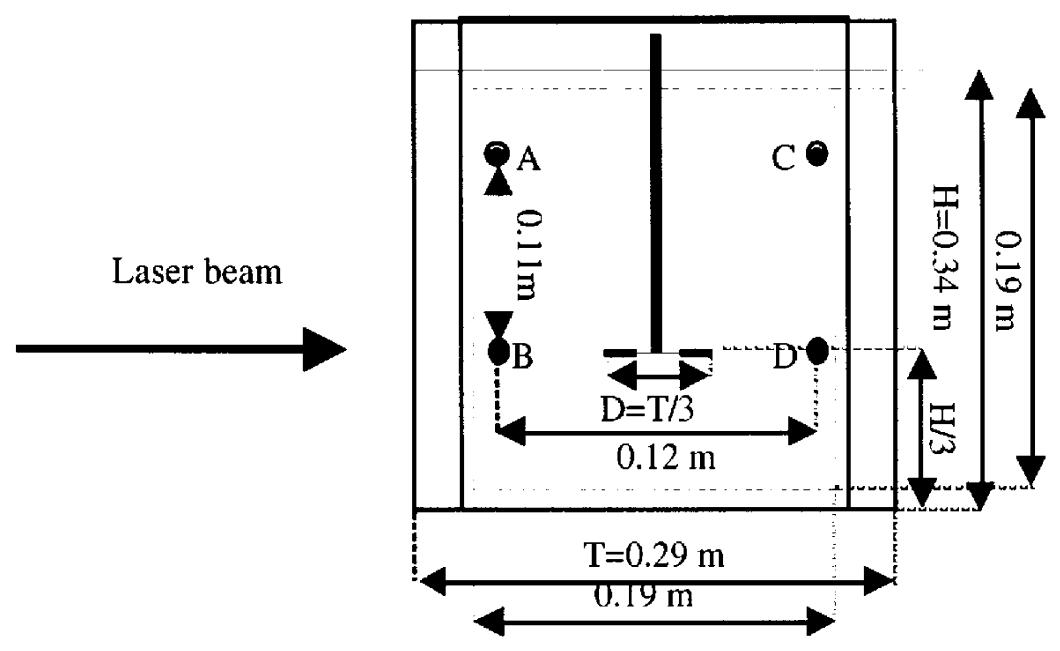

Figure 2. Mixing tank.

on a vertical and horizontal displacement system. This device is controlled by a computer with a total displacement of $0.54 \mathrm{~m}$ and a repeatability of $0.1 \mathrm{~mm}$. Two reservoirs continuously supply the tank with equal flow rates $\left(Q_{A}=Q_{B}=1.45 \times 10^{-3} \mathrm{~m}^{3} \mathrm{~min}^{-1}\right)$ by two incoming feed tubes. The tubes have an internal diameter of $6 \mathrm{~mm}$ and their axis are separated by a distance of $19.2 \mathrm{~mm}$. The feed point locations are at a height of $2 \mathrm{H} / 3$ and are situated on the tangential vertical plane to the impeller. In this plane, there is no significant orthogonal average velocity ${ }^{11}$. The tracer concentration $\left(40 \times 10^{-6} \mathrm{~kg} \mathrm{~m}^{-3}\right)$ is selected in the range of linearity between concentration and grey level (see Figure 3). The fluorescence images are recorded with FlowManager $^{\mathrm{B}}$-Dantec software and then processed in Aphelion $^{\circledR}$-Adcis images analysis software with specific developed macros.

\section{RESULTS}

Before starting the experiments in the continuous stirred tank, the range of the linear response between the grey level and the tracer concentration were determined. This was done at four points in Figure 2. It can be seen in Figure 3 that the linearity is observed up to $40 \times 10^{-6} \mathrm{~kg} \mathrm{~m}^{-3}(8.35 \times$ $10^{-5} \mathrm{~mol} \mathrm{~m}^{-3}$ ) with linear regression coefficient $R^{2}>0.99$ (least square method). For larger concentrations the response of the grey level becomes non-linear because of the exponential term of the equation (2). This result is in agreement with those obtained by Houcine et al. $^{5}$, who used a laser power of $1.4 \mathrm{~W}$. The linear response between the laser and fluorescence intensity is given on the Figure 4 (linear regression coefficient $\left.\mathrm{R}^{2}>0.99\right)$. In the range of

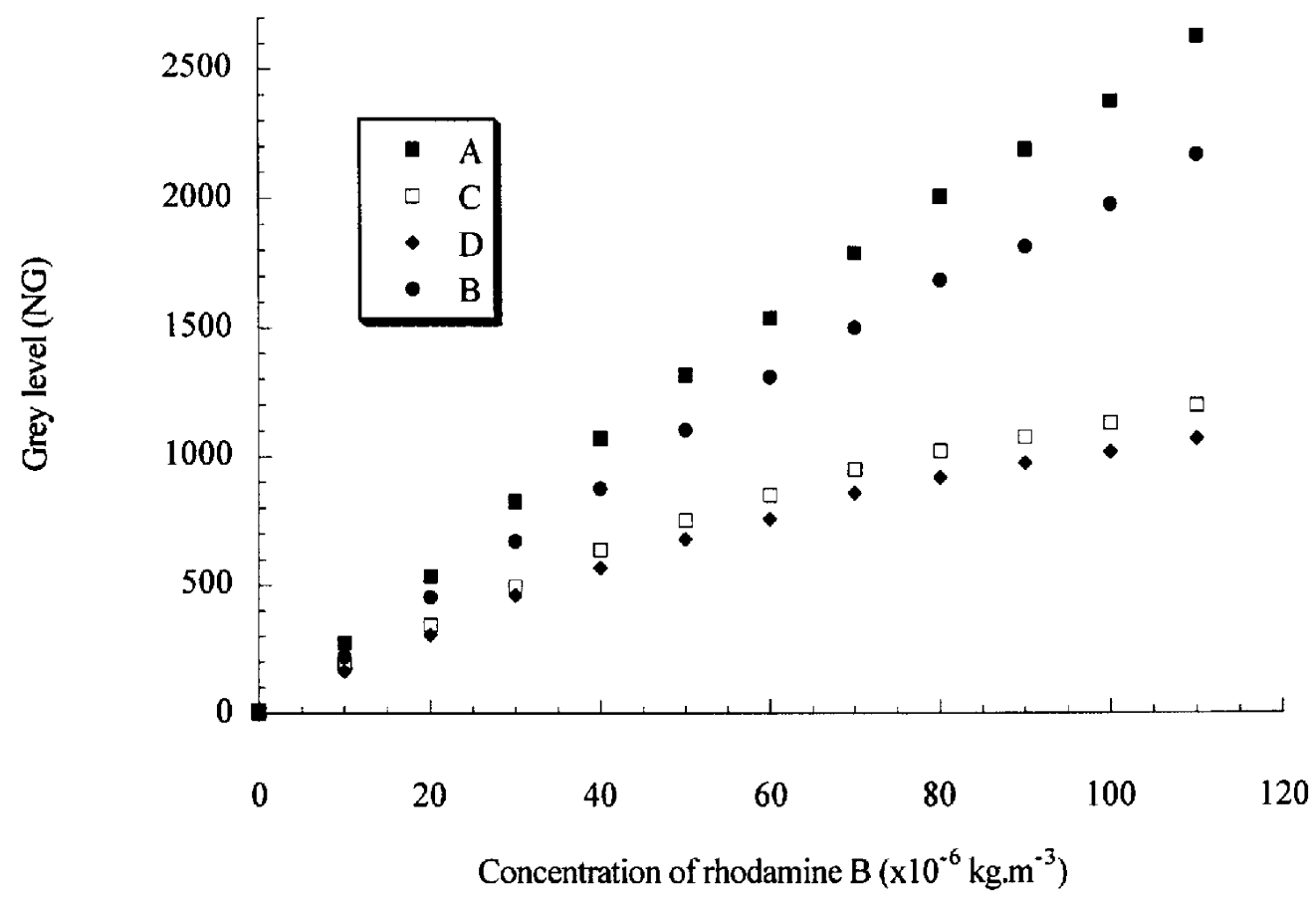

Figure 3. Grey level variation with tracer concentration. 


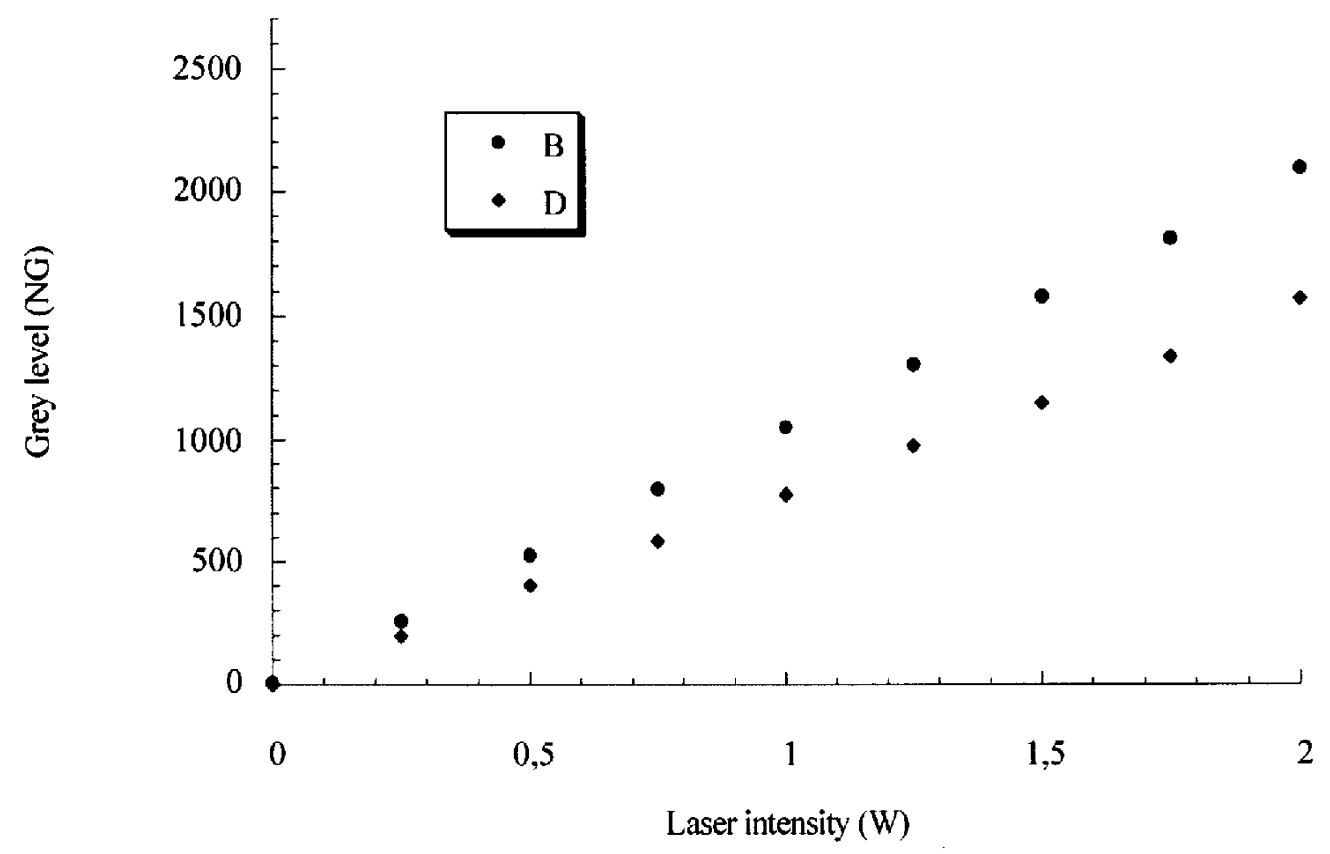

Figure 4. Grey level variation with laser intensity.

the tracer concentration $\left(0-40 \times 10^{-6} \mathrm{~kg} \mathrm{~m}^{-3}\right)$ and in the laser power range $(0-2 \mathrm{~W})$, there are no saturation problems.

An example of the instantaneous dye concentration field is shown in Figure 5 for the case of a continuously fed tank reactor: fluorescent tracer injected at $40 \times 10^{-6} \mathrm{~kg} \mathrm{~m}^{-3}$ appears white, whereas pure water appears black. The mean concentration field $\bar{C}(x, y)$ is obtained by averaging a number $n=100$ of successive instantaneous concentration fields $C(x, y, t)$. The reduced concentration $\bar{C}(x, y) /$ $\bar{C}_{m p}(x, y)$, Figure 6 , represents the relative deviation to perfect mixing. Along a line $A B$ (see Figure 6), the ratio varies between 0 (black) and 2 (white): Figure 7, corresponding to the feed stream of water and fluorescent tracer, respectively. Perfect mixing is reached for the value 1 .

The temporal variance is expressed by the following equation:

$$
\sigma^{2}(x, y, t)=\frac{1}{n} \sum_{k=1}^{n}(C(x, y, t)-\bar{C}(x, y))^{2}
$$

This equation characterizes the mixing dynamics. Figure 8 shows the field of the temporal variance corresponding to the mixing layers of both jets. A white area means high variance, while black means low variance. The persistence of two zones of intensive mixing can be observed around the injection cones at the exit of the feed point locations. The rest of the tank is well homogenized. There is almost no deviation of concentration from the mean.

All the previously shown fields characterize different aspects of the mixing process from the tracer concentration field. It is also interesting to have comparison tools to study various mixing situations. Thus, a mixing index is defined. In the case of two species $\mathrm{A}$ and $\mathrm{B}, \mathrm{Ablitzer}^{12}$ proposed:

$$
\alpha_{A B}(x, y, t)=1-\left|\frac{C_{A}(x, y, t)-C_{B}(x, y, t)}{C_{A}(x, y, t)+C_{B}(x, y, t)}\right|
$$

In the case of a tracer water solution (A) and pure water (B), the equation (4) becomes (see appendix), with the tracer concentration $C_{A}(x, y, t)$ :

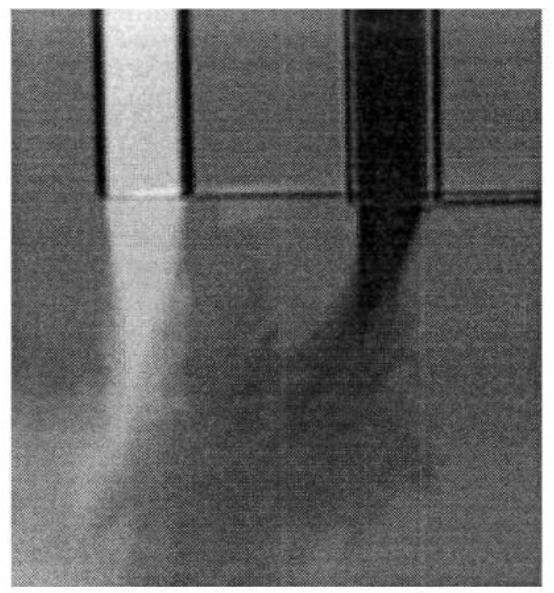

Figure 5. Instantaneous concentration field $C(x, y, t)$.

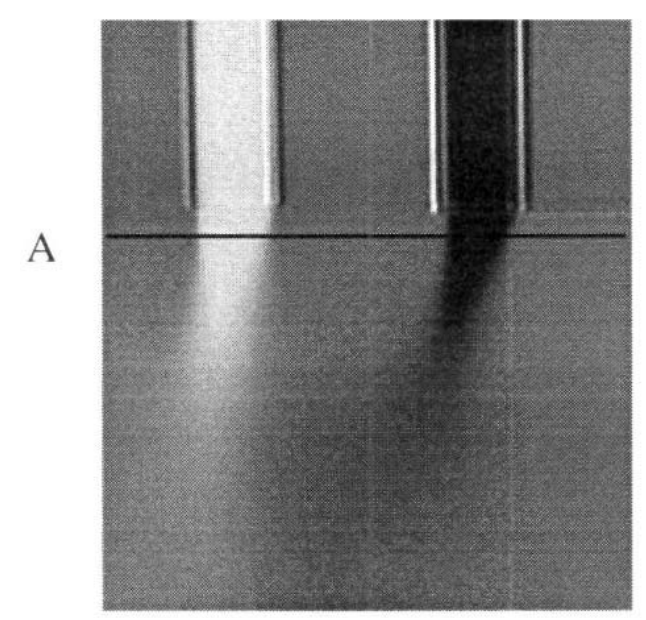

B

Figure 6. Reduced mean concentration $\bar{C}(x, y) / \bar{C}_{m p}(x, y)$. 


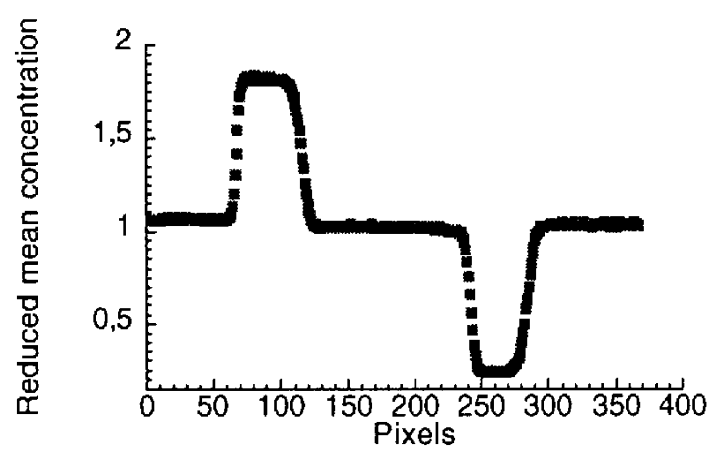

Figure 7. Reduced concentration variation along a line AB (in Figure 6).

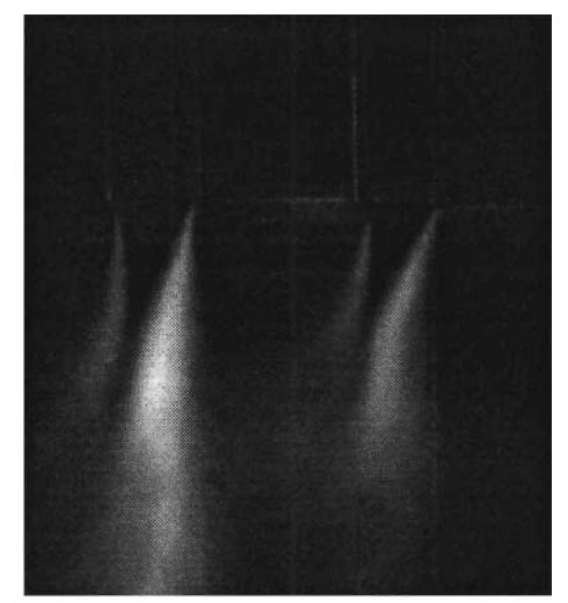

Figure 8 . Field of the instantaneous temporal variance $\sigma^{2}(x, y, t)$.

$$
\alpha_{A B}(x, y, t)=1-\left|\frac{C_{A}(x, y, t)-C_{A 0}}{C_{A}(x, y, t)^{*}\left(2^{*} \bar{f}-1\right)+C_{A 0}}\right|
$$

where: $\bar{f}=Q_{B} /\left(Q_{A}+Q_{B}\right)$

Examples of the instantaneous and average mixing index fields are shown in Figures 9 and 10, respectively. This index varies from 0 (black), in the feed streams jets corresponding to no contact up to a value close to 1 (white) in the rest of the tank. Figure 11 illustrates the evolution of this contacting parameter along the straight line AB (shown in Figure 10).

\section{CONCLUSION}

This work describes a powerful non-intrusive technique based on the fluorescence spectroscopy using a very thin static laser plane (down to $100 \mu \mathrm{m}$ ). The technique is validated for the case of a standard stirred tank reactor of $0.02 \mathrm{~m}^{3}$ volume, continuously fed with a tracer solution and pure water. Images of instantaneous and average concentration, fields of temporal variance, and mixing index are very precise and illustrate the investigative power and resolution of the PLIF technique. Thus, this device can be used to study contacting and mixing fluid patterns. This will allow, the study of influence of parameters, like feed rate ${ }^{13}$, feed position in the tank, and also allow more sophisticated mixing devices to be characterized.

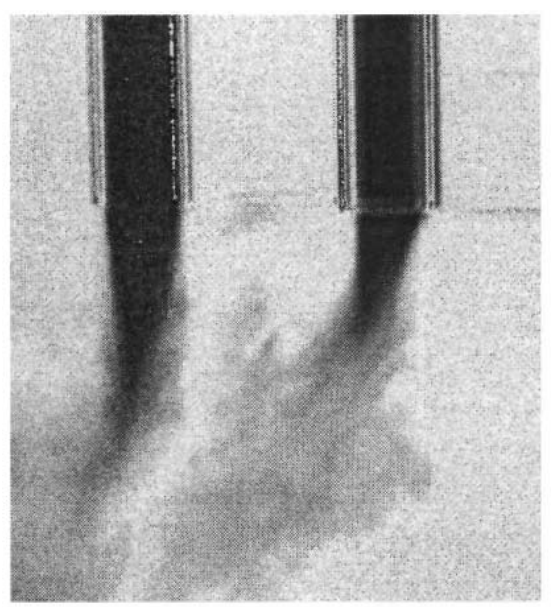

Figure 9. Instantaneous mixing index field.

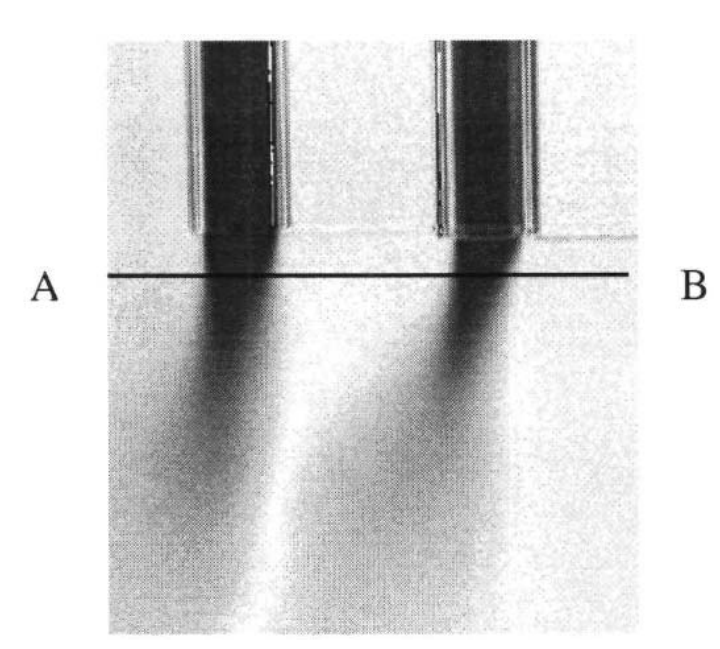

Figure 10. Mean mixing index field.

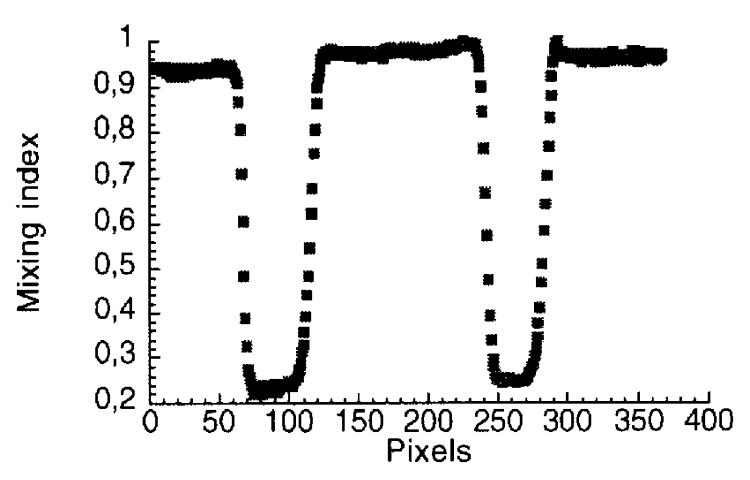

Figure 11. Variation of mean mixing index along a line $A B$ (in Figure 10).

\section{APPENDIX}

The aim of this appendix is to derive the mixing index $\alpha$ (given by equation (5)) in this case, from the one defined by Ablitzer ${ }^{12}$.

Consider the mixing of two inert tracers, without consumption, shown in Figure A1. If $f$ represents the instantaneous fraction of molecule coming from the inlet $\mathrm{B}$, at point $\mathrm{M}$ of coordinates $(x, y)$, the instantaneous concentrations of species A and B are respectively: 


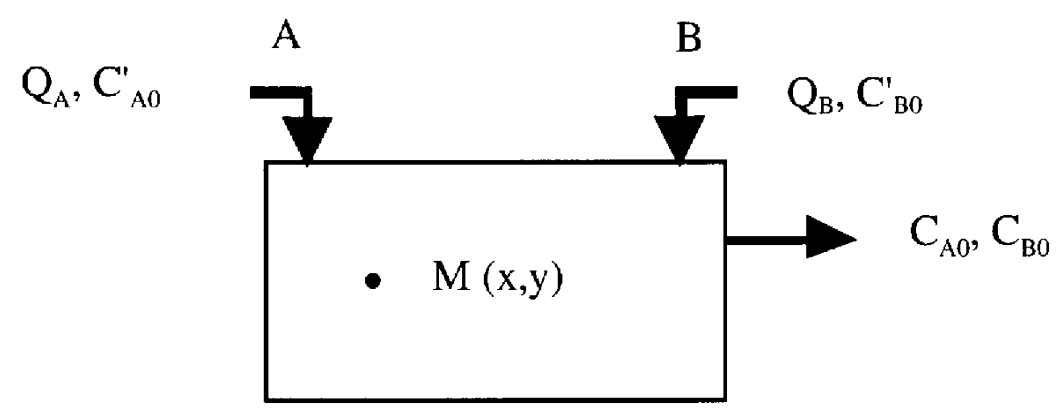

Figure A1. Mixing of two inert tracers without consumption.

$$
C_{A}=C_{A 0}^{\prime}(1-f)
$$

and:

$$
C_{B}=C_{B 0}^{\prime} f
$$

Thus, at the outlet:

$$
\begin{aligned}
& C_{A 0}=C_{A 0}^{\prime}(1-\bar{f}) \\
& C_{B 0}=C_{B 0}^{\prime} \bar{f}
\end{aligned}
$$

where

$$
\bar{f}=\frac{Q_{B}}{Q_{A}+Q_{B}}
$$

In the case of stoichiometry:

$$
Q_{A} C_{A 0}^{\prime}=Q_{B} C_{B 0}^{\prime}
$$

When equation (A6) is divided by $\left(Q_{A}+Q_{B}\right)$, it becomes:

$$
C_{A 0}^{\prime}(1-\bar{f})=\bar{f} C_{B 0}^{\prime}
$$

Addition of equations (A1) and (A2) leads to:

$$
\frac{C_{A}}{C_{A 0}^{\prime}}+\frac{C_{B}}{C_{B 0}^{\prime}}=1
$$

averaging gives:

$$
\frac{\bar{C}_{A}}{C_{A 0}^{\prime}}+\frac{\bar{C}_{B}}{C_{B 0}^{\prime}}=1
$$

For two species $A$ and $B$, Ablitzer ${ }^{12}$ proposed the following mixing index:

$$
\alpha_{A B}=1-\left|\frac{C_{A}-C_{B}}{C_{A}+C_{B}}\right|
$$

Taking into account the equation (A8), gives:

$$
\alpha_{A B}=1-\left|\frac{C_{A}-C_{B 0}^{\prime}\left(1-\frac{C_{A}}{C_{A 0}^{\prime}}\right)}{C_{A}+C_{B 0}^{\prime}\left(1-\frac{C_{A}}{C_{A 0}^{\prime}}\right)}\right|
$$

When $C_{B 0}^{\prime}$ is substituted from equation(A7), equation (A11) leads to:

$$
\alpha_{A B}=1-\left|\frac{C_{A}-C_{A 0}^{\prime} \frac{1-\bar{f}}{\bar{f}}\left(1-\frac{C_{A}}{C_{A 0}^{\prime}}\right)}{C_{A}+C_{A 0}^{\prime} \frac{1-\bar{f}}{\bar{f}}\left(1-\frac{C_{A}}{C_{A 0}^{\prime}}\right)}\right|
$$

After simplification, equation (A12) becomes:

$$
\alpha_{A B}=1-\left|\frac{C_{A}-(1-\bar{f}) C_{A 0}^{\prime}}{C_{A}\left(2^{*} \bar{f}-1\right)+C_{A 0}^{\prime}(1-\bar{f})}\right|
$$

Finally taking into account equation (A3), gives:

$$
\alpha_{A B}=1-\left|\frac{C_{A}-C_{A 0}}{C_{A}\left(2^{*} \bar{f}-1\right)+C_{A 0}}\right|
$$

\section{NOMENCLATURE}

$C \quad$ local concentration of the fluorescent dye, $\mathrm{molm}^{-3}$

$C_{X} \quad$ tracer concentration in the feedstream $\mathrm{X} \mathrm{mol} \mathrm{m}{ }^{-3}$

$C_{X 0} \quad$ concentration coming in the feedstream $\mathrm{X}$ at outing of the tank, $\mathrm{mol} \mathrm{m}^{-3}$

$C_{X 0}^{\prime} \quad$ initial concentration in the feedstream, $\mathrm{mol} \mathrm{m}^{-3}$

$C_{m p} \quad$ tracer concentration in the stirred tank in the completely homogeneous state, $\mathrm{molm}^{-3}$

$N G \quad$ grey level

$P_{o} \quad$ power of the laser source, $\mathrm{W}$

$\varepsilon_{i}, \varepsilon_{e} \quad$ extinction coefficient of incident laser light and emitted fluorescence light, $\mathrm{m}^{2} \mathrm{~mol}^{-1}$

$K \quad$ constant taking into account physical and geometrical parameters

$L \quad$ depth of penetration of the laser beam into the tracer solution, $m$

$L^{\prime} \quad$ optic path of the fluorescent light in the tracer solution, $\mathrm{m}$

$Q_{X} \quad$ feed rate of feedstream $\mathrm{X}$ entering the tank, $\mathrm{m}^{3} \mathrm{~s}^{-1}$

$(x, y) \quad$ pixel coordinates, $\mathrm{m}, \mathrm{m}$

$t$ time, s

\section{REFERENCES}

1. Villermaux, J. and David R., 1988, Effet du micromélange sur la précipitation, Journal de Chimie Physique, 85(2): 273-279.

2. Marcant, B. and David, R., 1991, Experimental evidence for and prediction of micromixing effects in precipitation, AIChE $J, 37(11)$ : 1698-1710.

3. David, R. and Marcant, B., 1994, Prediction of micromixing effects in precipitation: Case of double-jet precipitators, AIChE J, 40(3): 424-432.

4. Mahouast, M., 1993, Mesure des champs de concentration et de temperature dans un réacteur agité par traitement des images de la fluorescence induite par une nappe laser, Récent Progrès en Génie des Procédés, 24: 57-60.

5. Houcine, I., Vivier, H., Plasari, E., David, R. and Villermaux, J., 1996, Planar laser induced fluorescence technique for measurements of concentration fields in continuous stirred tank reactor, Experiments in Fluids, 22: 95-102.

6. Marcant, B., Seidlitz, F., Plasari, E. and Villermaux, J., 1997, Direct measurement of the generalized mixing model parameters by laser sheet visualization, Récent Progrès en Génie des Procédés, 11(51): 349-356.

7. Buchmann, M. and Mewes, D., 1998, Measurement of the local intensities of segregation with the tomographical dual wavelength photometry, Can J Chem Eng, 76: 626-630.

8. Van Cruyningen, I., Lozano, A. and Hanson, R. K., 1990, Quantitative imaging of concentration by planar laser-induced fluorescence, Experiments in Fluids, 10: 41-49. 
9. Gaskey, S., Vacus, P., David, R., Villermaux, J. and André, J. C., 1990, A method for study of turbulent mixing using flourescence spectroscopy, Engineering in Fluid, 9: 137-147.

10. Distelhoff, M.F.W. and Marquis, A. J., 2000, Scalar mixing in the vicinity of two disk turbines and two pitched blade impellers, Chem Eng Sci, 55: 1905-1920.

11. Kemoun, A., 1995, Caractérisation Expérimentale de la structure de l'écoulement dans une cuve agitée: Mélange, $\mathrm{PhD}$ Thesis (INPL, Nancy, France).

12. Ablitzer, C., 1999, Etude de la Formation de Poudre Dans des Jets coaxiaux réactifs, PhD Thesis (INPG, Saint-Étienne, France)
13. Fall, A., Lecoq, O. and David, R., 2001, Variation of the feed location and impeller speed in a stirred tank using Planar Laser Induced Fluorescence (P.L.I.F.), Récents Progrès en Génie des Procédés, 15: $25-32$.

\section{ADDRESS}

Correspondence concerning this paper should be addressed to R. David, Ecole Mines Albi-Carmaux, Campus Jarlard, Route de Teilet, 81013 Albi, Cedex 09, France. E-mail: rene.david@enstimac.fr 